\title{
STABILITY OF GAMMA PRIME IN H282: THEORETICAL AND EXPERIMENTAL CONSIDERATION
}

\author{
You-hai Wen ${ }^{1}$, Tian-le Cheng ${ }^{1}$, Paul D. Jablonski ${ }^{1}$, John Sears ${ }^{1}$, and Jeffrey A. Hawk ${ }^{1}$ \\ ${ }^{1}$ National Energy Technology Laboratory \\ 1450 Queen Avenue SW, Albany, OR 97321 United States
}

Keywords: Advanced Ultra Supercritical, Steam Turbine, Superalloy, Gamma Prime, Coarsening, Phase Field, Haynes 282

\begin{abstract}
The life cycle requirements for advanced Ni alloys are very demanding and can be on the order of several hundred thousand hours. Results are presented on a wrought Ni-based superalloy with a fixed amount of $\gamma^{\prime}$ strengthening phase, and either low Al or Ti (within the alloy specification). The effect that these changes have on the $\gamma^{\prime}$ misfit and its relevance to long term microstructural stability will be explored both experimentally as well as with computational modeling through 10,000 hours. Results on each alloy formulation are compared and discussed with respect to the long term stability of the alloy.
\end{abstract}

\section{Introduction}

Conventional coal-fired power plants utilize steam turbines to generate electricity and operate at efficiencies on the order of 35-37\% [1]. Operation at higher temperatures and pressures can lead to greater efficiencies, resulting in reduced fuel consumption and lower greenhouse gas emissions [2]. The goals of the U.S. Department of Energy's Advanced Power Systems Initiatives include Advanced Ultra Supercritical (A-USC) power generation from coal which requires steam conditions of up to $760^{\circ} \mathrm{C}$ and $35 \mathrm{MPa}$ [3]. Such systems have the ability to reach efficiencies on the order of $\geq 47 \%$. Higher efficiency will translate to reduced $\mathrm{CO}_{2}$ production for the same amount of energy produced, thereby facilitating a reduction in green-house gas emissions by reducing the amount of coal combusted, or if combined with carbon capture and sequestration, there will be less $\mathrm{CO}_{2}$ to capture and sequester. The terms subcritical, supercritical (SC), ultra-supercritical (USC), and A-USC for coal power plants are defined as follows: subcritical at below $22 \mathrm{MPa}$ and $375^{\circ} \mathrm{C}, \mathrm{SC}$ at above $22.1 \mathrm{MPa}$ and 538 to $565^{\circ} \mathrm{C}$, USC at above about $25 \mathrm{MPa}$ and $565^{\circ} \mathrm{C}$, and A-USC is above $700^{\circ} \mathrm{C}$ and $35 \mathrm{MPa}$. For A-USC conditions, nickel-base superalloys will have to be used for many components in the boiler and the turbine due to high temperature creep strength requirements $[1,3]$.

One of the leading candidate alloys for both boiler and turbine application is Haynes 282, due to its favorable combination of processing, strength, ductility, and weldability in comparison to other wrought Ni-base superalloys such as Nimonic 105, Haynes 263, and INCONEL® 740 among others. Nickel-base superalloys are conventionally wrought processed, contain $\mathrm{Cr}, \mathrm{Mo}$, and $\mathrm{Co}$ in significant mass fractions, and are strengthened mainly by $\gamma^{\prime}$ precipitation from the addition of $\mathrm{Al}$ and $\mathrm{Ti}$. It has been well established that a balance of $\mathrm{Al}$ and $\mathrm{Ti}$ is crucial in order to maintain a low $\gamma / \gamma^{\prime}$ misfit for optimal creep performance in nickel based superalloys [4]. In this work the role of chemistry variation is evaluated within the alloy specification as it applies to alloy strength and $\gamma^{\prime}$ formation and coarsening. 


\section{Background}

In looking at conventional Haynes 282, and with the balance of the alloy additions set to nominal within the specification range, the $\mathrm{Al}$ or $\mathrm{Ti}$ concentration were subsequently varied to either a low level while the other $\gamma^{\prime}$ stabilizer was then adjusted such that the amount of $\gamma^{\prime}$ was as nearly identical as possible for both alloy variants. Figure 1 shows a plot of weight fraction of phases versus temperature for a Haynes 282 alloy with low $\mathrm{Al}$, and with the Ti level then adjusted to obtain 16.8 wt. $\% \gamma^{\prime}$ at $800^{\circ} \mathrm{C}$. This version of Haynes 282 will be subsequently referred to as H282-B.

Figure 2 shows a plot of weight fraction of phase versus temperature for a Haynes 282 alloy with low $\mathrm{Ti}$, and with the $\mathrm{Al}$ level adjusted to obtain $16.8 \mathrm{wt} . \% \gamma^{\prime}$ at $800^{\circ} \mathrm{C}$. This version of Haynes 282 will be referred to as $\mathrm{H} 282-\mathrm{C}$, henceforth. The two plots appear to predict essentially the same amount of equilibrium constituent phases, including $\mathrm{M}_{6} \mathrm{C}, \mathrm{M}_{23} \mathrm{C}_{6}$ and $\mathrm{Mu}$ phase. However, close examination reveals that the amount of $\gamma^{\prime}$ increases as temperature decreases in a similar, but not identical way such that at $500^{\circ} \mathrm{C}$ alloy $\mathrm{H} 282-\mathrm{C}$ would have $24.7 \mathrm{wt} . \% \gamma^{\prime}$ while alloy H282-B would have $23.4 \mathrm{wt} . \% \gamma^{\prime}$. Thus, it is important that these two alloys be compared at $800^{\circ} \mathrm{C}$, or very close to $800^{\circ} \mathrm{C}$, where the fraction of $\gamma^{\prime}$ is equivalent, or nearly so.

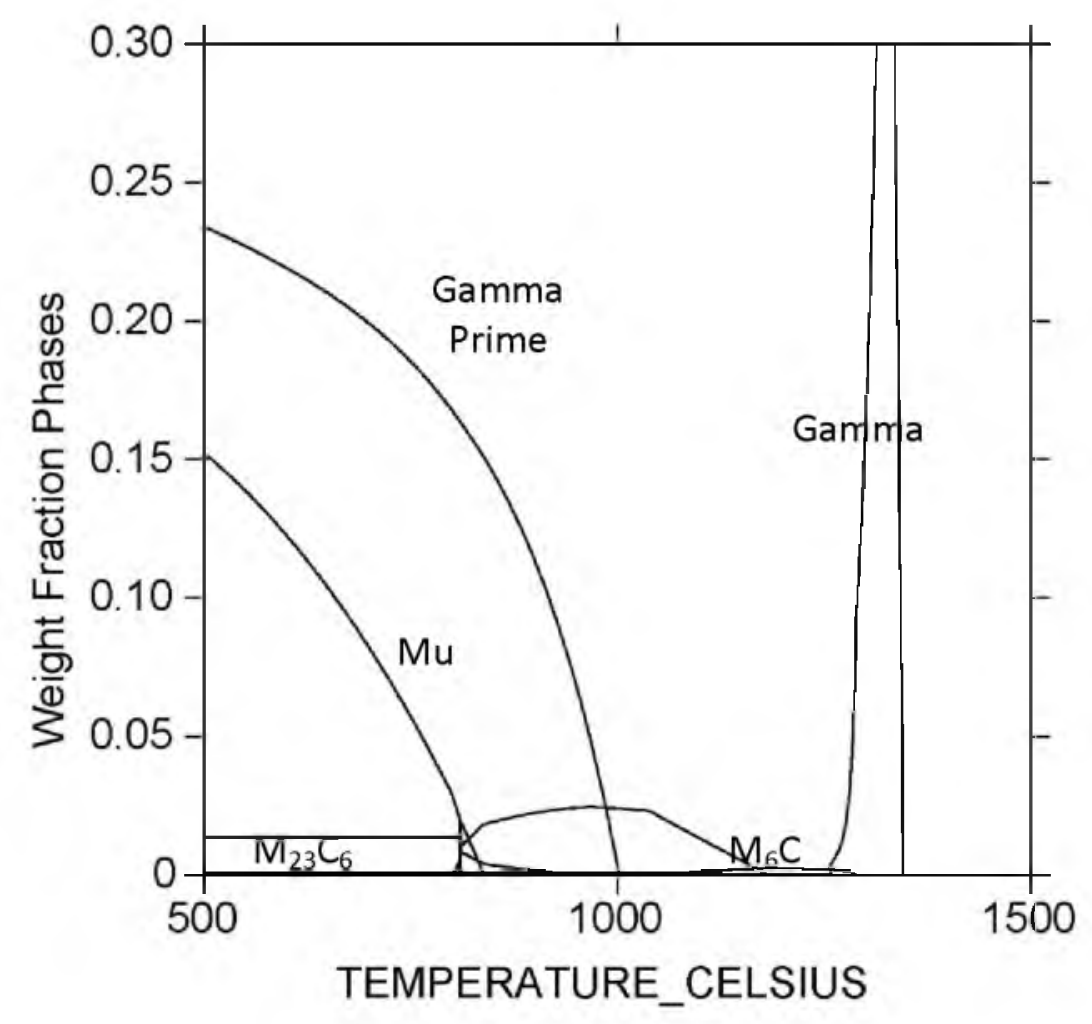

Figure 1: The equilibrium weight fraction of phases for Haynes 282 is plotted as a function of temperature for the alloy with low Al content, and with the Ti level then adjusted to obtain 16.8 wt. $\% \gamma^{\prime}$ at $800^{\circ} \mathrm{C}(\mathrm{H} 282-\mathrm{B})$ 


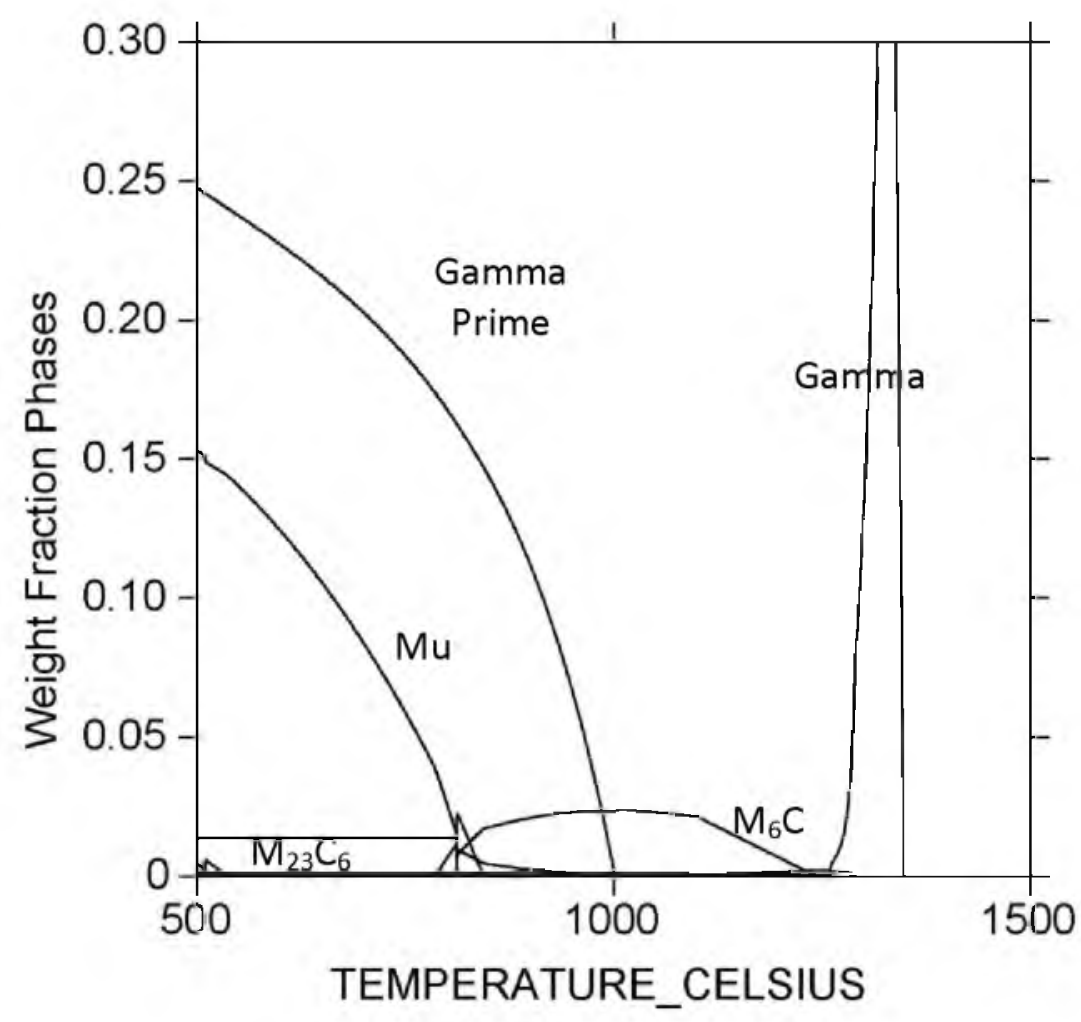

Figure 2: The equilibrium weight fraction of phases for Haynes 282 is plotted as a function of temperature for the alloy with low $\mathrm{Ti}$ content, and with the Al level adjusted to obtain $16.8 \mathrm{wt}$ \% $\gamma^{\prime}$ at $800^{\circ} \mathrm{C}(\mathrm{H} 282-\mathrm{C})$.

The actual chemistries in the final consolidated ingots varied slightly from the aim ones with minimal losses of both $\mathrm{Al}$ and $\mathrm{Ti}$ (Table I). For example, H282-B contained $1.27 \mathrm{wt} . \% \mathrm{Al}$ and $2.22 \mathrm{wt}$ \% Ti versus the aim levels of $1.38 \mathrm{wt}$. \% Al and $2.24 \mathrm{wt}$. \% Ti. Likewise, H282-C contained $1.54 \mathrm{wt}$ \% $\mathrm{Al}$ and $1.94 \mathrm{wt}$ \% Ti versus the aim levels of $1.65 \mathrm{wt} . \% \mathrm{Al}$ and $1.97 \mathrm{wt} . \%$ Ti. This variation in actual alloy chemistry with reduced levels of $\mathrm{Al}$ and Ti resulted in a reduction in the predicted phase fraction of $\gamma^{\prime}$ at $800^{\circ} \mathrm{C}$ from the design value of $16.8 \mathrm{wt} . \%$, leading to actual $\gamma^{\prime}$ phase fractions of $15.8 \mathrm{wt} . \%$ and $15.6 \mathrm{wt}$. \%, respectively, for alloys H282-B and $\mathrm{H} 282-\mathrm{C}$. However, for convenience these phase fractions are considered identical for the purposes of this comparison study.

Table I: The experimental alloy chemistry for H282-B and H282-C is given below along with the nominal Haynes 282 chemistry range.

\begin{tabular}{cccccccccccc}
\hline Alloy & $\mathrm{Ni}$ & $\mathrm{Cr}$ & $\mathrm{Co}$ & $\mathrm{Mo}$ & $\mathrm{Ti}$ & $\mathrm{Al}$ & $\mathrm{Fe}$ & $\mathrm{Mn}$ & $\mathrm{Si}$ & $\mathrm{C}$ & $\mathrm{B} \mathrm{ppm}$ \\
\hline Nominal & Bal & $18.5-$ & $9-$ & $8-$ & $1.9-$ & $1.38-$ & $1.5^{*}$ & $0.3^{*}$ & $0.15^{*}$ & $0.04-$ & $30-50$ \\
& & 20.5 & 11 & 9 & 2.3 & 1.65 & & & & 0.08 & \\
$\mathrm{H} 282-\mathrm{B}$ & $\mathrm{Bal}$ & 19.22 & 9.86 & 8.49 & 2.22 & 1.27 & & 0.25 & 0.15 & 0.08 & 100 \\
$\mathrm{H} 282-\mathrm{C}$ & $\mathrm{Bal}$ & 19.19 & 9.85 & 8.50 & 1.94 & 1.54 & & 0.25 & 0.14 & 0.08 & 100 \\
\hline
\end{tabular}

*Maximum value

In previous research on $\mathrm{H} 282-\mathrm{B}$ and $\mathrm{H} 282-\mathrm{C}$ [6], the calculated amount of $\gamma^{\prime}$ lattice mismatch with the matrix phase for the two alloys in the heat treated condition is presented in Figure 3. 
Both alloys show a slight negative mismatch ranging from about $-0.10 \%$ to about $-0.14 \%$ at $800^{\circ} \mathrm{C}$. This negative mismatch appears to have minimal consequences on morphology since both alloys contain spherical $\gamma^{\prime}$ precipitates. From a mechanical behavior point of view, the effect of high and low Ti and Al contents in producing the same amount of $\gamma^{\prime}$ but with a $40 \%$ difference in $\gamma^{\prime}$ lattice mismatch also did not appear to have a significant effect on the creep behavior. Similar rupture lives at the same stress level and similar creep stress exponents suggest the same deformation mechanism are dominant during secondary creep, and similar modes of deformation and damage accumulation suggest that these features of the microstructure outweigh the influence of any intrinsic strengthening effects dictated by a different degree of lattice mismatch due to chemistry differences of $\gamma^{\prime}$ in each alloy.

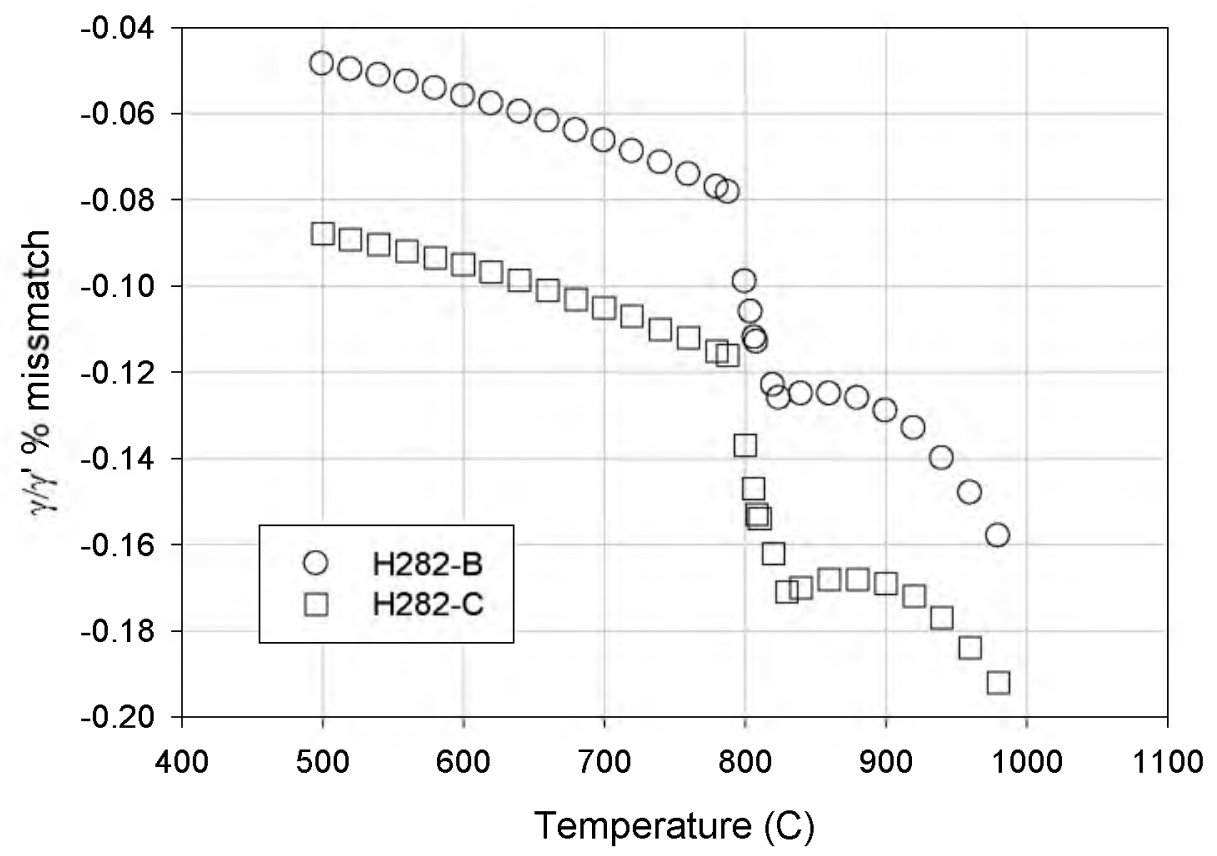

Figure 3: The $\gamma^{\prime}$ misfit for H282-B and H282-C with matrix $\gamma$ is shown as a function of temperature $\left(\gamma / \gamma^{\prime}\right.$ misfit calculated using JMatPro [6]).

\section{Phase Field Modeling}

A multi-component microstructure simulation model has been developed based on phase field methodology and CALPHAD techniques [7]. The details of model development were developed in that manuscript and will not be repeated here. Thermodynamic database for Ni-base superalloys from ThermoCalc and atomic mobility database for $\gamma$ developed by Campell [8-9] were used in that work. Mobility database for $\gamma^{\prime}$ is not universally available, and as such, the composition-independent atomic mobilities for solute elements in $\gamma^{\prime}$ phase were used instead, whose values, due to the ordered structure, are two orders of magnitude smaller than those in matrix $\gamma$ phase. The mobility data for $\gamma^{\prime}$ are listed in Table II and were taken as $1 / 100$ of the corresponding values for matrix $\gamma$ phase at the equilibrium nominal composition for Haynes 282 The databases provide thermodynamic and kinetic information to the phase field model through PanEngine as developed by CompuTherm LLC [10]. Two-dimensional simulations were performed using $256 \times 256$ grids. 
Table II: Atomic Mobility Data for $\gamma^{\prime}$ Phase, $10^{-24} \mathrm{~mol} \cdot \mathrm{m}^{2} /(\mathrm{J} \cdot \mathrm{s})$

\begin{tabular}{ccccccc}
\hline $\mathbf{A l}$ & $\mathbf{C o}$ & $\mathbf{C r}$ & $\mathbf{F e}$ & $\mathbf{M o}$ & $\mathbf{T i}$ & $\mathbf{N i}$ \\
3.129 & 1.055 & 1.227 & 0.982 & 1.847 & 7.491 & 0.746 \\
\hline
\end{tabular}

Application of the phase field model for Haynes 282 demonstrated its unique capability by providing some guidance as to alloy chemistry design for desired long-term microstructure stability based on $\gamma^{\prime}$ particle coarsening. Six simulated H282 alloys, each with a slightly different composition, were selected for virtual simulation and subsequent stability testing. The nominal chemical compositions are provided in Table III. Note the change in $\gamma^{\prime}$ phase fraction from the chemistry changes. Remember the rationale behind H282-B and H282-C alloy design. While the experimental approach is not an exact match to the phase field simulations, it is expected that the isothermal annealing experiments will result in different $\gamma^{\prime}$ coarsening rates that can be used to tune future phase field simulations.

Table III: Simulated Alloy Compositions, wt. \%.

\begin{tabular}{ccccccccc}
\hline Alloy & Al & Co & Cr & Fe & Mo & Ti & Ni & Vol.\% $\boldsymbol{\gamma}^{\prime}$ \\
\hline$\# 1 *$ & 1.5 & 10.0 & 20.0 & 1.5 & 8.5 & 2.1 & Bal & 18.86 \\
$\# 2$ & $\underline{\mathbf{1 . 8}}$ & 10.0 & 20.0 & 1.5 & 8.5 & 2.1 & Bal & 21.08 \\
$\# 3$ & 1.5 & $\underline{\mathbf{1 1 . 0}}$ & 20.0 & 1.5 & 8.5 & 2.1 & Bal & 18.91 \\
$\# 4$ & 1.5 & 10.0 & $\underline{\mathbf{2 1 . 0}}$ & 1.5 & 8.5 & 2.1 & Bal & 18.97 \\
$\# 5$ & 1.5 & 10.0 & 20.0 & 1.5 & $\underline{\mathbf{9 . 5}}$ & 2.1 & Bal & 19.05 \\
$\# 6$ & 1.5 & 10.0 & 20.0 & 1.5 & 8.5 & $\underline{\mathbf{2 . 5}}$ & Bal & 21.62 \\
\hline
\end{tabular}

*typical nominal composition of Haynes 282

The simulations carried out in this research are shown in Figure 4. The various curves for each simulated alloy indicate distinct disparities due to the alloying effects described in Table III. Comparing with simulation results for Alloy \#1, Alloy \#2 has a shortened initiation stage followed by a faster coarsening rate as indicated by the increased slope of curve. This leads to the largest particle size after 200 hours of exposure at $760^{\circ} \mathrm{C}$, in spite of the smallest initial $\gamma^{\prime}$ particle starting size. This result shows the effect of increased $\mathrm{Al}$ weight fraction on accelerating $\gamma^{\prime}$ particle coarsening.

On the opposite side from these curves are Alloys \#3, \#4, \#5 and \#6. For the simulated alloys \#3, $\# 4$ and $\# 5, \gamma$-rich elements $\mathrm{Co}, \mathrm{Cr}$ and $\mathrm{Mo}$, respectively, have been added. Chromium seems to have a larger effect on $\gamma^{\prime}$ particle coarsening even though its relative composition change is the smallest amongst these three elements. More surprising is the response in Alloy \#6 with the increase in $\mathrm{Ti}$, which shows the slowest $\gamma^{\prime}$ particle coarsening rate of these four cases. The strong negative effect due to increased $\mathrm{Ti}$ is quite contrary to the effect that $\mathrm{Al}$ has on $\gamma^{\prime}$ kinetics. The low mobility of $\gamma$-stabilizers $\mathrm{Co}, \mathrm{Cr}$ and Mo slows down the $\gamma^{\prime}$ coarsening rate. Chromium also reduces the chemical potential, and hence diffusion, of $\mathrm{Al}$ in matrix $\gamma$ which magnifies this effect. However, addition of $\mathrm{Cr}$ may be unfavorable due to its propensity to precipitate the detrimental $\sigma$ phase. 


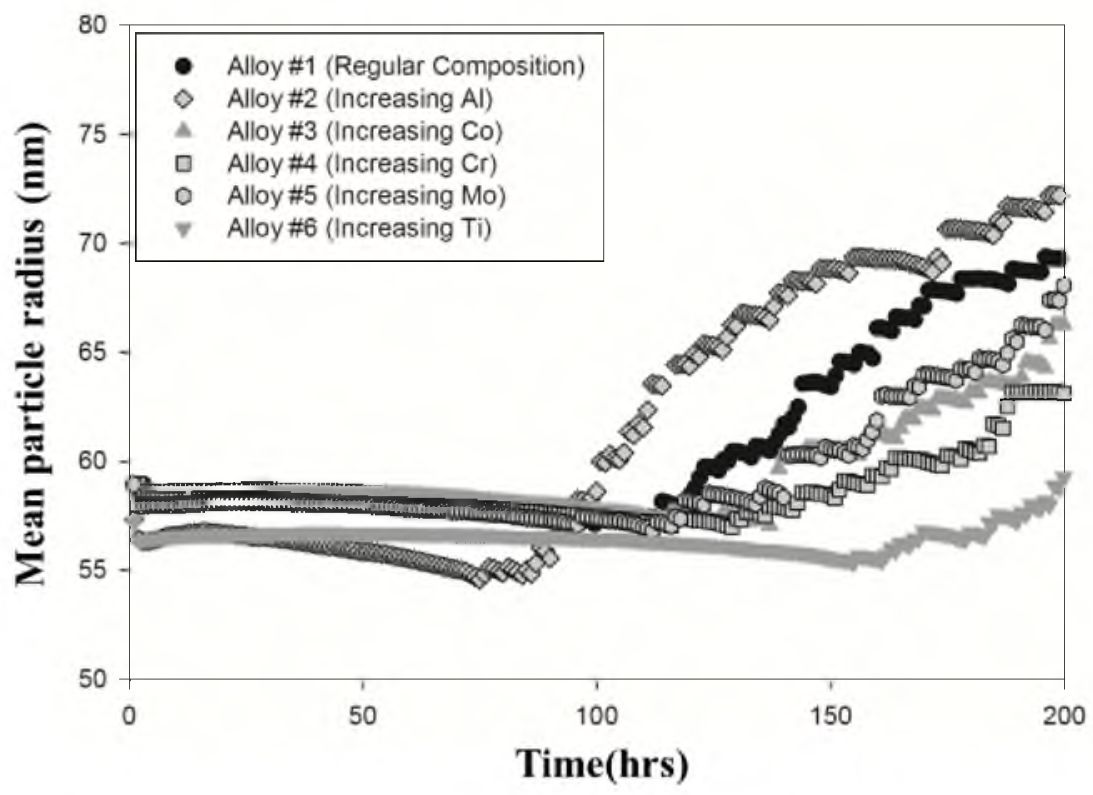

Figure 4: Temporal average $\gamma^{\prime}$ particle size changes in simulated $\mathrm{H} 282$ alloys due to composition modification as listed in Table II as a function of isothermal exposure at $760^{\circ} \mathrm{C}$.

Aluminum tends to increase the $\gamma^{\prime}$ particle coarsening rate because it increases the mobility in the matrix $\gamma$ phase as well as increasing $\gamma^{\prime}$ volume fraction. Replacement of Al with another $\gamma^{\prime}$ former, $\mathrm{Ti}$, seems feasible in alleviating the rate of particle coarsening while maintaining $\gamma^{\prime}$ phase fraction. The effect of $\mathrm{Ti}$ is interesting as it substantially decelerates the $\gamma^{\prime}$ particle coarsening kinetics, even though its atomic mobility is comparable with that of Al. One of the possible reasons for this is that the solute partition of Ti between $\gamma^{\prime}$ and $\gamma$ is higher than that of Al. The concentration difference of Ti between $\gamma^{\prime}$ and $\gamma$ for Alloy \#6 is 12.5 at. \%, while that of $\mathrm{Al}$ for Alloy \#2 is 10.0 at. \%. Titanium solubility in matrix $\gamma(\sim 0.2$ at. \%) is also the smallest among all the solute elements, in comparison with $\sim 1.7$ at. $\%$ for $\mathrm{Al}$. It also does not increase with increasing overall alloy composition. The larger solute partition causes slower mass transport across the $\gamma / \gamma^{\prime}$ interface. This effect is augmented by much lower mobility in the $\gamma^{\prime}$ phase. It also causes a longer transport distance in the $\gamma$ matrix as it obtains a sufficient supply of solute. The low solubility in $\gamma$ also decreases the mass transport, which can be explained by the intrinsic flux [7]. Therefore, a small concentration leads to a lower flux, and hence, a slower coarsening rate.

\section{Experimental}

Computational thermodynamic modeling tools (ThermoCalc [11]) were first used to model the alloy phase contents at temperature to ensure the comparison of alloys with differing chemistries yet identical phase contents. Each heat of Haynes 282 was formulated from high purity raw materials. The alloys were designed with either the Ti or Al set to a low level and the other $\gamma^{\prime}$ stabilizing element then adjusted such that the total phase fraction of $\gamma^{\prime}$ remained identical for both alloy variants. The balance of the alloy constituents were set to the nominal of the Haynes 282 chemistry. The $\gamma^{\prime}$ misfit of each alloy was determined computationally using JMatPro software [6].

Each alloy formulation was melted in a vacuum induction furnace and cast with $50^{\circ} \mathrm{C}$ superheat above the ThermoCalc predicted liquidus temperature for that alloy formulation. A $75 \mathrm{~mm}$ 
diameter round graphite mold was used for the casting, which also incorporated a zirconia wash coat to prevent additional pickup of carbon above the desired limit. After casting, the hot-top for each ingot was removed, followed by sectioning a $2 \mathrm{~mm}$ thick diametrical slice for chemical analysis. The transition element chemistries were determined by wavelength dispersive x-ray fluorescence with a Rigaku ZSX Primus II and utilizing NIST traceable standards (i.e., with a reported accuracy of 0.01 wt. \%). Carbon chemistries were determined with a LECO CS444LS, utilizing NIST certified standards (in this case with reported accuracy to $0.002 \mathrm{wt}$. \%).

To ensure the fidelity of experiments, a multi-step homogenization heat treatment [5] was used prior to thermo-mechanical processing (TMP) to better disperse the alloy constituents, and thus, reduce segregation. The homogenized ingots were bagged in protective stainless steel foil pouches and preheated at $1175^{\circ} \mathrm{C}$ for 3 hours prior to TMP. Thermo-mechanical processing at NETL makes use of a scaled down version of industrial techniques, namely hot forging followed by hot rolling. The initial ingot was subsequently worked from the round casting into slab shape. Subsequent, hot rolling reduced the slab into plate with a thickness of approximately $10 \mathrm{~mm}$. The rolled plate was then solution heat treated at $1037^{\circ} \mathrm{C}$ for 30 minutes followed by a water quench. $\mathrm{X}$-ray diffraction and transmission electron microscopy (TEM) failed to detect $\gamma^{\prime}$. The solution heat treated plate was then cut into $10 \mathrm{~mm} \times 10 \mathrm{~mm} \times 25 \mathrm{~mm}$ blanks for isothermal annealing experiments.

The rectangular sample blanks were isothermally exposed at $760^{\circ} \mathrm{C}$ from 1 hour to 5,051 hours for each of two Haynes 282 compositions (identified as B and C). Once the predetermined time interval was reached, a rectangular blank was removed from the furnace and quenched in water. From this blank a $3 \mathrm{~mm}$ diameter pin was extracted via electro-discharge machining. A Struers Minitom precision cut-off machine was employed to produce several $3 \mathrm{~mm}$ diameter thin slices of the material for each condition and alloy. These slices were subsequently mechanically ground and polished from both sides until a thickness of approximately $100 \mu \mathrm{m}$ was achieved. Transmission electron microscopy (TEM) thin foils were produced from these prepared slices by dual-jet electropolishing with a Struers TenuPol-5. The electrolyte was comprised of $200 \mathrm{ml} 60 \%$ perchloric acid in $800 \mathrm{ml}$ absolute ethyl alcohol, and was used at a temperature of $-16^{\circ} \mathrm{C}$, with an applied potential of $22 \mathrm{~V}$. Polishing time to perforation was typically of the order of 1.5 to 2 minutes. Prepared thin foils were cleaned in a series of baths - first water, then methanol, and finally two rinses with ethyl alcohol; after which the foils were air dried and stored.

TEM observations were made in a Philips/FEI CM200 operated at $200 \mathrm{kV}$, where axial dark field (DF) imaging was used to reveal the $\gamma^{\prime}$ phase. Several imaging conditions were attempted, and some of the strongest DF contrast was found when using a 110 superlattice reflection with the $\gamma$ matrix tilted just a few degrees from a $<110>$ zone axis. Since preliminary observations of the $\gamma^{\prime}$ particles suggested they were essentially spherical in form, the specific orientation used during the recording of images was of no consequence. However, it became quite apparent that the strongest possible DF contrast is necessary for the shorter aging time samples, where the diameter of the $\gamma^{\prime}$ particles is significantly less than the thickness of optimum regions of the TEM foils.

Images were recorded on traditional cut film (wet chemical processing) over a range of magnifications from 38,000 to 150,000 . Image magnification was chosen to suit the sample's microstructure, where each recorded field of view incorporated a worthwhile number of $\gamma^{\prime}$ particles, but with those particles enlarged sufficiently to facilitate easy and accurate measurement. Selected DF images were digitized at 800 dpi using a desktop scanner in the transmitted light mode. 


\section{Particle Size Analysis}

Gamma prime particle sizes were measured using ImageJ public domain software [12]. In preparation for this aspect of the work, each useful TEM magnification was verified, and the integrity of the scale-bar that would be written to the TEM film was confirmed for each of those magnifications. The scanner used for image digitization was assessed to ensure that it was not introducing unacceptable aspect ratio (or other) distortions. Additionally, a set of $\gamma^{\prime}$ particles were measured manually (directly from the TEM negative, using an eye loupe with a graticule marked in $0.1 \mathrm{~mm}$ increments). Gamma prime size assessments by both ImageJ and the manual method were in acceptably good agreement. It was also confirmed that ImageJ was quite capable of handling images of different magnifications within a single dataset, so long as appropriate scaling information was entered at each magnification change.

The particle size assessment process involved several steps for each selected DF image:

1) The image contrast and brightness were optimized (though this was done with sufficient care and only to the limit whereby the perceived particle size was neither dilated nor eroded).

2) Using the ImageJ "thresholding" tool, a mask was overlaid on the image, indicating the recognized particles. Here again, operator influence was carefully controlled, ensuring that the mask was the best possible fit to the perceived particle sizes.

3) Having applied the threshold mask, extraneous image debris was removed (painted out) Sources of debris included weak contrast from carbides, small perforations in the foil, and the microscope's image information panel, etc. Particles cut by the boundary of the image required no special treatment, as ImageJ automatically eliminated those from the particle size assessment.

4) 'Surgery' was performed on overlapping and/or touching particles. The width of the 'knife' was selected as narrowly as possible while allowing reproducible functionality, to minimize the influence on particle size. Even so, a slight reduction in the size of two adjacent particles was considered more acceptable than the apparent doubling of the size of one.

5) Next, the image was set into a binary mode.

6) Magnification information was then applied to the image, so the results would be presented in 'real' units ( $\mathrm{nm}$ for example, rather than pixels).

7) Selection of the 'Analyze Particle Sizes' function caused ImageJ to fit an ellipse to each recognized particle and report the major and minor ellipse axis dimensions, as well as the area of each recognized particle. At this point, the operator was able to survey the match between the particles and the ellipse overlay. If necessary, adjustments were made (if, for example, additional refinement was required) and the particle size assessment would then be rerun. Results were saved in spreadsheet form, and it was also possible to generate distribution histograms of particle size (either by area, or major/minor ellipse dimension).

Particle size measurements from several DF images were accumulated into one dataset for each composition and aging condition sample. On average, more than 1,000 $\gamma^{\prime}$ particles were measured for each dataset. Although spanning a period of several weeks, each step of this process has been applied in the most consistent manner possible, by a single operator, with checks along the way to ensure good reproducibility.

Whereas it is easy enough to calculate the average diameter from the reported area of each measured particle, initial assessment of these data has been made from the reported major and 
minor ellipse axis dimensions. Monitoring two dimensions potentially provided more information regarding shape. Discovering that the $\gamma^{\prime}$ particles remained essentially spherical throughout all aging times, the quoted diameter of each particle has been determined as $\tilde{d}=2 \sqrt{S / \pi}$ where $S$ is the area of the particle. This area equivalent diameter $(\tilde{d})$ is identical to the geometric mean of the major and minor axes of the fitted ellipse.

Noticing a minor shape change for the $\gamma^{\prime}$ particles at longer aging times (from spherical, to very slightly cuboidal) a second set of DF images were recorded for one sample, using a 110 superlattice reflection near a $\langle 100\rangle$ zone axis. Comparing the particle size results at two different orientations $(<110>$ and $<100>)$ it was possible to demonstrate that imaging orientation did not significantly affect the $\gamma^{\prime}$ size measurement.

Due to the nature of TEM imaging a two-dimensional projection of the three-dimensional volume element of the investigated sample appears on the viewing screen. As a consequence particles may be totally within the volume element or particles may be sectioned equal to, or less than, the real particle diameter during preparation. There is often associated with measurement of this type a certain degree of discrepancy between the actual particle size and the apparent TEM observations of particle size. In the analysis of data presented here a particle-size correction algorithm, originally proposed by Saltikov et al. [13], has been utilized to account for this possible discrepancy. This algorithm assumes spherical particles and that the spatial distribution of particles is statistically uniform within the volume and also isotropic so that the microstructural morphology in one thin foil is considered to be representative of the bulk material. Corté and Leibler [14] extended the Saltikov algorithm to include the 'projection' effect that is caused by the finite thickness of the foil, in addition to the 'cross-section' effect. As to which effect predominates during coarsening would depend on the particle size as compared to the foil thickness. In making use of this algorithm, the histogram of the actual particle size distribution is linked to the original histogram of the size distribution from the TEM image through a conversion matrix $\mathbf{A}$. The elements of $\mathbf{A}$ are defined as

$$
\left\{\begin{array}{l}
A_{i j}=0, \text { if } i>j \\
\left.A_{i j}=H \delta_{i j}+\Delta\left(\sqrt{(j+1)^{2}-i^{2}}\right)-\sqrt{j^{2}-i^{2}}\right), \text { if } i \leq j
\end{array} .\right.
$$

Here $\delta_{i j}$ is the Kronecker delta and $H$ is the foil thickness. The conversion can then be simply written in tensorial form as:

$$
\mathbf{N}_{V}=\mathbf{A}^{-1} \mathbf{N}_{A},
$$

In Eq. (2) $\mathbf{A}^{-1}$ is the inverse of $\mathbf{A}$, where $\mathbf{N}_{A}(i)$ stands for number of particles per unit area with apparent diameter within the range $[i \Delta,(i+1) \Delta]$, and $\mathbf{N}_{v}(i)$ stands for the number of particles per volume with actual diameter within the same range. It should be noted that by chance a particle may be blocked by a bigger particle upon imaging. Such an effect is often neglected, as is in this work.

\section{Results and Discussion}

Collecting the fields of view in the TEM for the $\gamma^{\prime}$ particles size was relatively easy once they achieved a diameter of approximately $15-20 \mathrm{~nm}$. At this size and above imaging the particles in dark field (DF) mode was fairly straightforward. Dark field imaging utilizes one of the less

intense diffraction spots near the central spot and creates a "reverse" image of sorts. That is, the 
$\gamma^{\prime}$ particles are now bright against a dark/black background, making particle identification and measurement easier. Below this size the intensity of the $\gamma^{\prime}$ particles is weak and as such it is more difficult to obtain clear images. Figure 5 shows a dark field image for $\gamma^{\prime}$ particles from H282-B annealed to 100 hours where the mean $\gamma^{\prime}$ particle diameter was approximately $31 \mathrm{~nm}$. From each image field it was possible to identify and measure between 250 and 350 particles. From several image fields it was possible to measure in excess of 1000 particles. For the H282-B sample annealed for 100 hours, measurements on 1547 particles were used to determine the apparent mean diameter for $\gamma^{\prime}$.

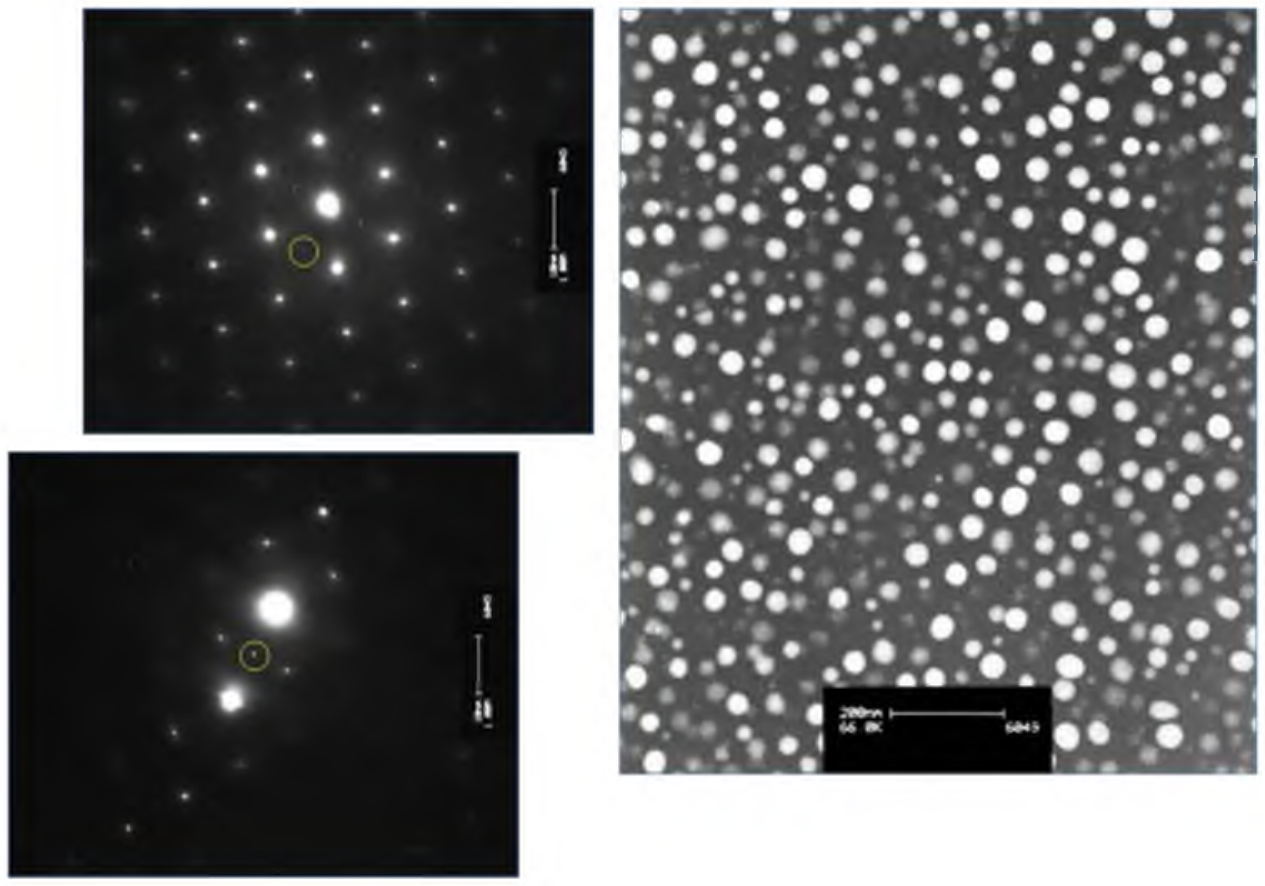

Figure 5: For $\mathrm{H} 282-\mathrm{B}$ annealed at $760^{\circ} \mathrm{C}$ for 100 hours, reasonably good DF contrast was obtained with a 110 superlattice reflection at a $<110>$ zone axis. The relative intensity of that reflection (circled in the diffraction patterns) increases when tilting away from the exact zone axis (ZA) orientation.

From a practical perspective as the size of the apparent mean $\gamma^{\prime}$ particle increased, the magnification used to generate an image similar in nature to that of Figure 5 became easier. On the other hand as the $\gamma^{\prime}$ particle diameter decreased it was increasingly more difficult to image the particles due to weak diffraction contrast in DF mode as well as TEM stability (i.e., drift of the electron beam during long exposure times).

Take for example the case of samples exposed for 1 hour. For this short exposure duration little opportunity exists for the $\gamma^{\prime}$ particle to nucleate and grow to any appreciable size. Imaging the particles in bright field mode is also difficult because contrast between the matrix and particle is very slight. The intensity of the $\gamma^{\prime}$ superlattice reflections in the selected area diffraction patterns is also weak, and when one of these superlattice reflections is used to image in DF, the intensity of the DF image is very weak as well. In any event it was possible to image the particles at 1,4 , $10,16,25,50$ and 75 hours where the particle diameters for H282-B ranged from $4.8 \mathrm{~nm}$ to 26 $\mathrm{nm}$ (similar particle diameters for $\mathrm{H} 282-\mathrm{C}$ ). A representative image from the H282-B sample annealed for 1 hour is shown in Figure 6. As can be seen, or not so clearly seen, the $\gamma^{\prime}$ superlattice reflections in the SADP are very weak (note arrowed reflections). The lack of 
superlattice intensity meant that imaging individual particle was difficult. From the TEM field of view in Figure 6 only about 98 particles were useable to determine the $\gamma^{\prime}$ particle diameter.
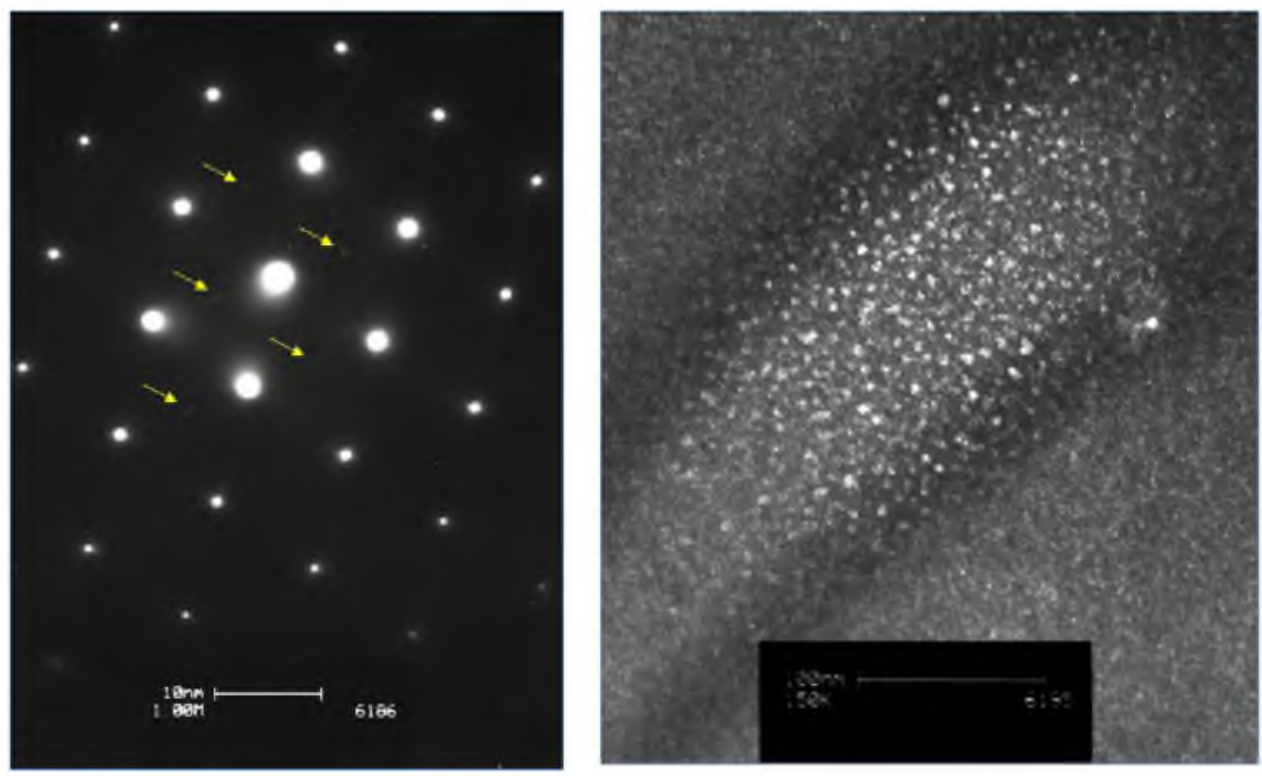

Figure 6: Dark field (DF) images were attempted using a 110 superlattice reflection near a $<110>$ zone axis. The diffraction pattern shows extremely weak intensity from the $\gamma^{\prime}$ phase. So far, only one useable but very limited DF image has been recorded (shown cropped, at right).

The same procedure was used throughout to determine the uncorrected $\gamma^{\prime}$ particle diameter for the H282-B and H282-C alloys after isothermal annealing. Once this data had been collected, it was corrected for TEM foil thickness. It was assumed that a certain fraction of particles near the upper and lower foil surfaces were truncated in some manner due to sectioning and specimen preparation activities. These particles would appear "smaller" than the true diameter. As such a correction algorithm as previously described was systematically employed to adjust $\gamma^{\prime}$ particle size due to the effects of truncation.

Table IV shows the results of the exact average of the measured original $\gamma^{\prime}$ particle diameters $\left(1^{\text {st }}\right.$ row of data). As mentioned in the Experimental Section, this correction algorithm was applied to the fitted particle size from the TEM images $(\tilde{d})$ in all stages. The foil thickness was chosen to be $50 \mathrm{~nm}$ (i.e., $H$ ) based on TEM foil thickness measurements. There is, however, unavoidably some uncertainty in the foil thickness for the TEM samples even within one field of view. For this sake, and to better understand how the foil thickness affects the correction, two additional values of $H$ were tested further and these results for the B-series samples are shown in Table $\mathrm{V}$ and Figure 7. In contrast, the $\gamma^{\prime}$ particle sizes in the remaining rows of Table $\mathrm{V}$ are calculated using histograms, i.e., the size of all particles in one bin of the histogram is counted simply identical to the bin size and adjusted accordingly with respect to TEM foil thickness. This leads to a slight difference in the measured $\gamma^{\prime}$ particle diameter. This is shown in Table $\mathrm{V}$ for $\mathrm{H} 282-\mathrm{B}$ and Table VI for H282-C.

It was observed that the larger $H$ is, the smaller the discrepancy between the corrected size and the apparent size is, which is due to the fact that larger values of $H$ lead to more significant projection effects. In contrast, smaller values of $H$ lead to larger corrections. Therefore, assuming a zero foil thickness would cause serious overestimates of particle size especially at early stages. The best estimate for the most possible foil thickness fluctuation in these samples 
would be $50 \mathrm{~nm}$ to $75 \mathrm{~nm}$. For situations encountered in these annealing experiments, the mean corrected particle size is larger than the mean apparent particle size. The discrepancy is relatively small at early stage of particle growth when the $\gamma^{\prime}$ particles are small. In this case the projection effect predominates. However, at later stages where $\gamma^{\prime}$ coarsening is well underway, the crosssection effect becomes predominant and the correction is appreciable.

During coarsening, the particle size can typically be fitted by a power function of time, i.e.:

$$
<d>^{n} \propto t
$$

The classical Lifshitz-Slyozov-Wagner (LSW) theory predicts a cubic growth, i.e., $n=3$ [15], which is classified as matrix-diffusion-controlled (MDC) coarsening [16]. In addition, Ardell pointed out that there exists a different regime where the interface between particle and matrix is the diffusion bottleneck, which results in so-called trans-interface-diffusion-controlled (TIDC) coarsening, with a temporal exponent of $n$ between 2 and 3 [16-17]. This typically occurs when there is large disparity of diffusivities in the disordered $\gamma$ phase and the ordered $\gamma^{\prime}$ phase.

A log-log plot of $\langle d\rangle \sim t$ relationship of the B-series samples shows linear behavior with a slope approximately $1 / 2.5$, or more exactly 0.39 , which implies $<\mathrm{d}>^{2.5} \alpha t$ (Figure 8). It appears that the coarsening of $\gamma^{\prime}$ precipitates in H282-B does show behavior similar to TIDC. It must be remembered that the above theories consider only relatively simple situations, such as a binary or ternary alloy. For the $\mathrm{H} 282$ system, the situation is more complicated by the number of alloying elements in the alloy. Regardless, the two extreme-situation (i.e., either MDC or TIDC) predictions from these theories are still instructive as to what diffusion processes may be occurring. Further refined study is, however, required to obtain more quantitative results.

Table IV: Mean apparent $\gamma^{\prime}$ spherical particle diameters for H282-B and H282-C.

\begin{tabular}{|c|c|c|c|c|c|c|c|c|c|c|c|c|}
\hline Time (h) & 1 & 4 & 10 & 16 & 25 & 50 & 75 & 100 & 500 & 1176 & 2252 & 5051 \\
\hline H282-B & 4.7 & 8.7 & 11.4 & 13.2 & 16.9 & 21.5 & 24.2 & 29.5 & 48.1 & 63.5 & 79.5 & 101.6 \\
\hline H282-C & 7.4 & 10.0 & 11.4 & 15.3 & 16.3 & 22.6 & 24.3 & 28.1 & 45.1 & 60.6 & 89.4 & 103.5 \\
\hline
\end{tabular}

Table V: Mean apparent particle size and corrected size for H282-B at selected annealing times with different assumed foil thickness ( $H=25 \mathrm{~nm}, 50 \mathrm{~nm}$, and $75 \mathrm{~nm}$, respectively).

\begin{tabular}{|c|c|c|c|c|c|c|c|c|c|c|c|c|}
\hline Time (hours) & 1 & 4 & 10 & 16 & 25 & 50 & 75 & 100 & 500 & 1176 & 2252 & 5051 \\
\hline $\begin{array}{c}\text { Mean particle size } \\
\text { (exact, in nm) }\end{array}$ & 4.70 & 8.65 & 11.4 & 13.2 & 16.9 & 21.5 & 24.2 & 29.5 & 48.1 & 63.5 & 79.5 & 102 \\
\hline $\begin{array}{c}\text { Mean apparent } \\
\text { particle } \\
\text { size (nm) }\end{array}$ & 4.73 & 9.03 & 12.0 & 14.1 & 18.1 & 23.1 & 26.1 & 31.7 & 51.6 & 67.7 & 85.3 & 110 \\
\hline $\begin{array}{c}\text { Corrected size } \\
\text { with } \\
H=25(\mathrm{~nm})\end{array}$ & 4.73 & 9.03 & 12.2 & 14.4 & 19.1 & 25.2 & 29.0 & 37.2 & 63.8 & 83.1 & 108 & 167 \\
\hline $\begin{array}{c}\text { Corrected size } \\
\text { with } \\
H=50(\mathrm{~nm})\end{array}$ & 4.73 & 9.03 & 12.1 & 14.2 & 18.7 & 24.3 & 27.7 & 34.8 & 58.8 & 77.4 & 100 & 148 \\
\hline $\begin{array}{c}\text { Corrected size } \\
\text { with } \\
H=75(\mathrm{~nm})\end{array}$ & 4.73 & 9.03 & 12.1 & 14.2 & 18.5 & 23.9 & 27.2 & 33.9 & 56.7 & 74.8 & 96.7 & 139 \\
\hline
\end{tabular}


${ }^{*}$ Particle size in this row is exact average of the original particle diameter (geometric mean of the major and minor axes of fitted ellipses, Table IV).

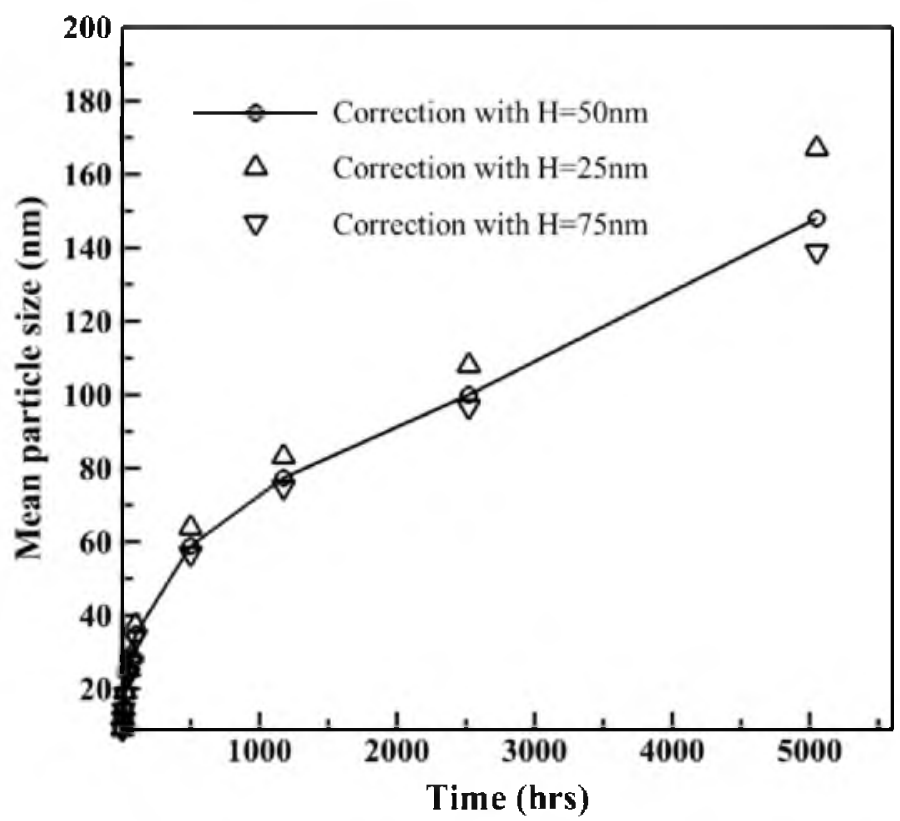

Figure 7: The relationship between the mean particle size (corrected) for $\mathrm{H} 282-\mathrm{B}$ and aging time (hours) is shown with different assumed foil thicknesses $(H)$.

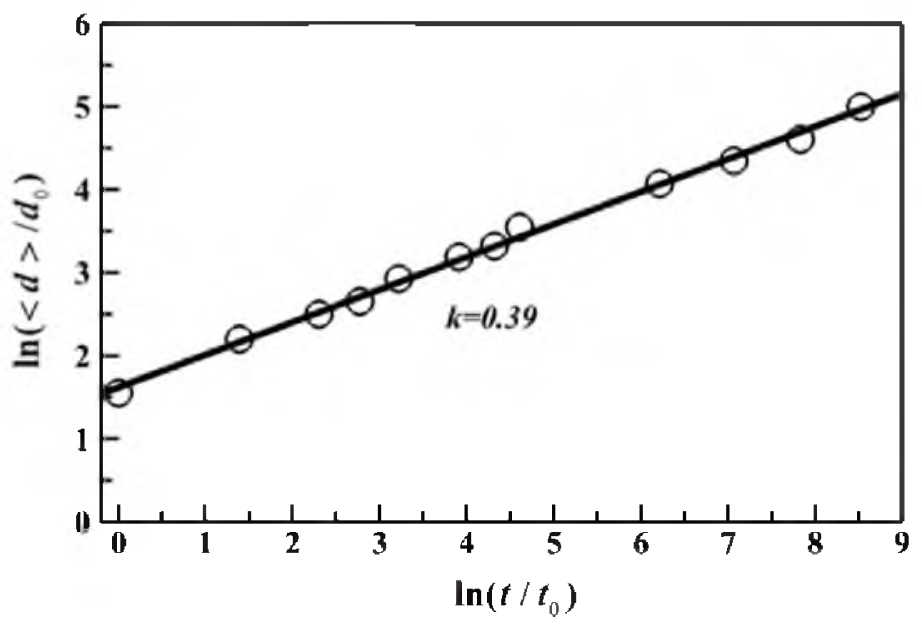

Figure 8: Replot of $\ln \left(<d>/ d_{0}\right)$ versus $\ln \left(t / t_{0}\right)$ for coarsening of $\gamma^{\prime}$ in H282-B shows a quasilinear relationship. The slope of the linear fit is approximately 0.39 , where $d_{0}=1 \mathrm{~nm}$ and $t_{0}=1$ hour.

The exact same analysis was performed on the $\mathrm{H} 282-\mathrm{C}$ alloy. Details on $\gamma^{\prime}$ particle diameters are shown in Table VI. Figure 9 shows the change in $\gamma^{\prime}$ particle diameter with isothermal annealing time. The general shape of the $\mathrm{H} 282-\mathrm{C}$ curve is slightly "flatter" for times greater than 2252 hours. Figure 10 shows a plot of $\left.\ln (<d\rangle / d_{0}\right)$ versus $\ln \left(t / t_{0}\right)$ for coarsening of $\gamma^{\prime}$ in H282-C and in this case the slope of the data is close to $1 / 2.5$, or more exactly 0.37 .

In comparing the $\gamma^{\prime}$ particle diameters measured for $\mathrm{H} 282-\mathrm{C}$ with the $\mathrm{H} 282-\mathrm{B}$, two trends were observed. The H282-B $\gamma^{\prime}$ particle diameters are slightly smaller for times up to 25 hours. 
However, the absolute magnitude difference given the error in measurement is pretty insignificant. Up through about 1176 hours the coarsening behavior as measured by $\gamma^{\prime}$ particle diameters is roughly the same. At this point a slight divergence occurs in terms of the rate of increase in particle diameter with exposure time. For the H282-B alloy continues in a relatively uniform rate as noted in Figure 7 and Figure 11, where both H282-B and H282-C are shown on the same graph. The H282-C alloy continues to exhibit a sharp increase that flattens out for the 5051 hour sample, hinting at a change in the coarsening rate. One additional sample of each alloy is still at temperature and will be withdrawn at about 10,000 hours of exposure. At this point it may be possible to better identify the coarsening kinetics trend for each alloy.

Table VI: Mean apparent particle size and corrected size for $\mathrm{H} 282-\mathrm{C}$ at selected annealing times with different assumed foil thickness ( $H=25 \mathrm{~nm}, 50 \mathrm{~nm}$, and $75 \mathrm{~nm}$, respectively)

\begin{tabular}{|c|c|c|c|c|c|c|c|c|c|c|c|c|}
\hline Time (hours) & 1 & 4 & 10 & 16 & 25 & 50 & 75 & 100 & 500 & 1176 & 2252 & 5051 \\
\hline $\begin{array}{c}\text { Mean particle size } \\
\text { in nm) }\end{array}$ & 7.36 & 9.97 & 11.4 & 15.3 & 16.3 & 22.6 & 24.3 & 28.1 & 45.1 & 60.6 & 89.4 & 104 \\
\hline Mean particle size (nm) & 7.52 & 10.4 & 12.0 & 16.4 & 17.4 & 24.2 & 26.0 & 30.2 & 48.8 & 65.4 & 97.4 & 111 \\
\hline $\begin{array}{c}\text { Corrected size with } H=25 \\
(\mathrm{~nm})\end{array}$ & 7.53 & 10.5 & 12.3 & 17.1 & 18.2 & 26.7 & 28.9 & 34.7 & 61.9 & 86.5 & 149 & 154 \\
\hline $\begin{array}{c}\text { Corrected size with } H=50 \\
(\mathrm{~nm})\end{array}$ & 7.53 & 10.5 & 12.2 & 16.7 & 17.9 & 25.6 & 27.6 & 32.8 & 56.7 & 79.0 & 132 & 140 \\
\hline $\begin{array}{c}\text { Corrected size with } H=75 \\
(\mathrm{~nm})\end{array}$ & 7.53 & 10.5 & 12.2 & 16.6 & 17.7 & 25.2 & 27.1 & 32.0 & 54.5 & 75.4 & 123 & 133 \\
\hline
\end{tabular}

Particle size in this row is exact average of the original particle diameter (geometric mean of the major and minor axes of fitted ellipses).

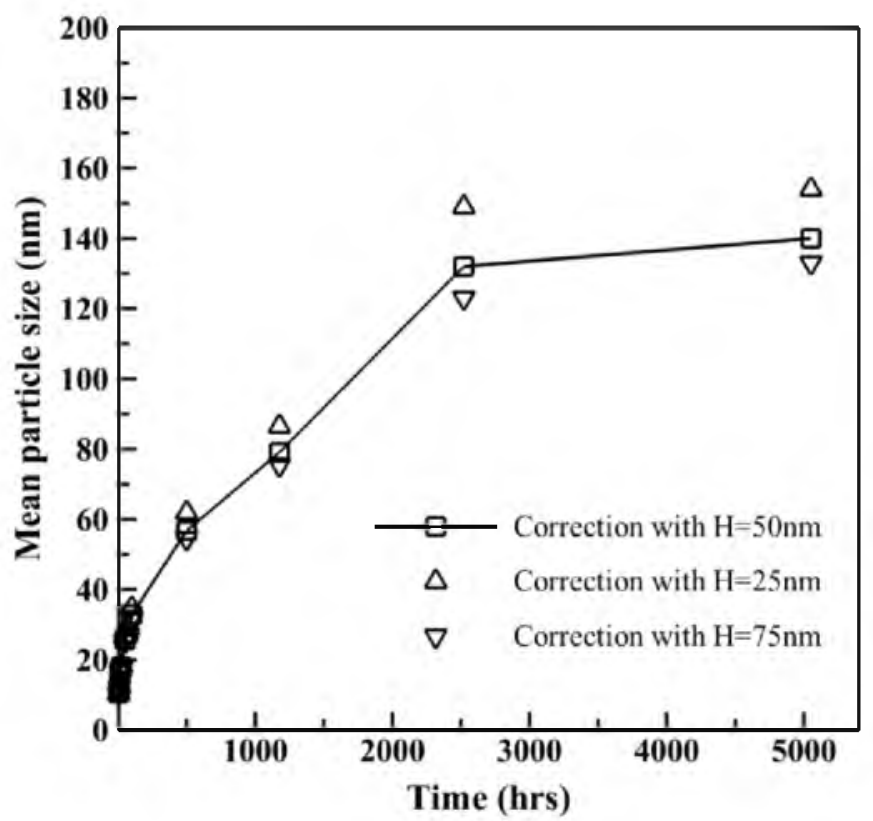

Figure 9: The relationship between the mean particle size (corrected) for H282-C and aging time (hours) is shown with different assumed foil thicknesses $(H)$. 


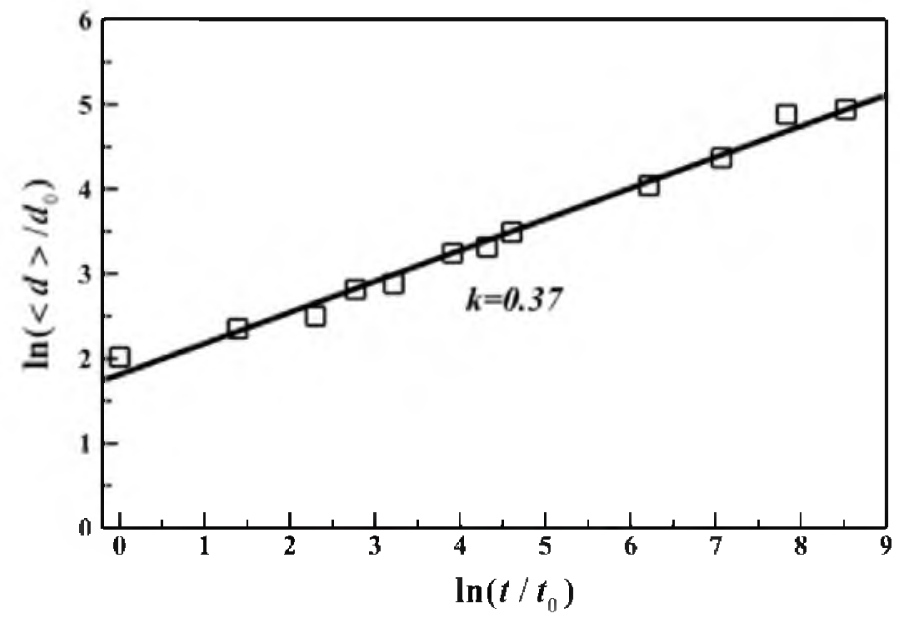

Figure 10: Replot of $\ln \left(<d>/ d_{0}\right)$ versus $\ln \left(t / t_{0}\right)$ for coarsening of $\gamma^{\prime}$ in H282-C shows a quasi-linear relationship. The slope of the linear fit is approximately 0.37 , where $d_{0}=1 \mathrm{~nm}$ and $t_{0}=1$ hour

Figure 11 shows the mean particle diameter for $\gamma^{\prime}$ as a function of isothermal exposure time for both $\mathrm{H} 282$ alloys. As mentioned previously, through 1176 hours the coarsening behavior of both the H282-B and H282-C alloys is very similar, almost identical for all intents. At the next interval, divergence in coarsening appears and this trend continues in the interval after. One more sample at 10,000 hours will be measured. At this point the apparent nature of the emerging trend will either be verified or refuted.

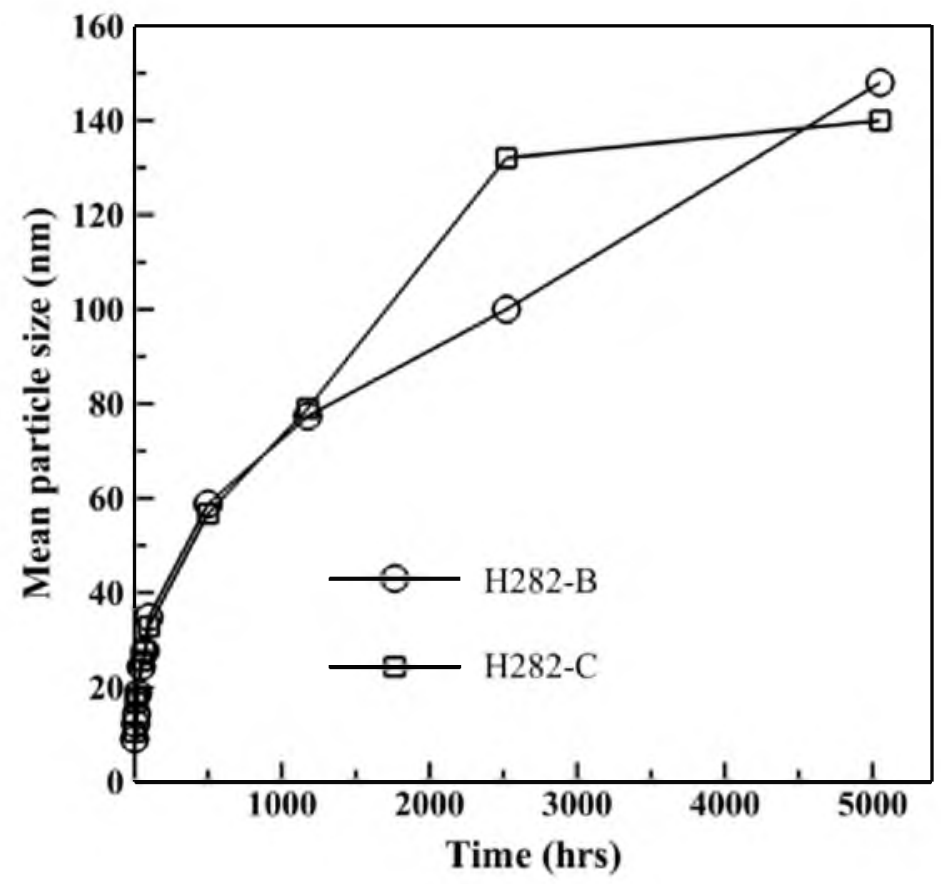

Figure 11: The relationship between the mean particle size (corrected) for H282-B and H282-C and aging time (hours) with $50 \mathrm{~nm}$ foil thickness $(H)$ is shown.

Figure 12 shows the combined data for both H282-B and H282-C in terms of the $\ln \left(\langle d\rangle / d_{0}\right)$ versus $\ln \left(t / t_{0}\right)$ for coarsening of $\gamma^{\prime}$. The solid line is the linear fit of the H282-B data set, or the 
one with $n=0.39$. While there is some variation in the H282-C data, most of it superposes exactly on the H282-B. While not exactly equivalent to the value of $n$ for trans-interfacediffusion-controlled (TIDC) coarsening, it is surprisingly close and it would make sense given the very similar nature of the $\gamma$ matrix in the $\mathrm{H} 282-\mathrm{B}$ and $\mathrm{H} 282-\mathrm{C}$ variants.

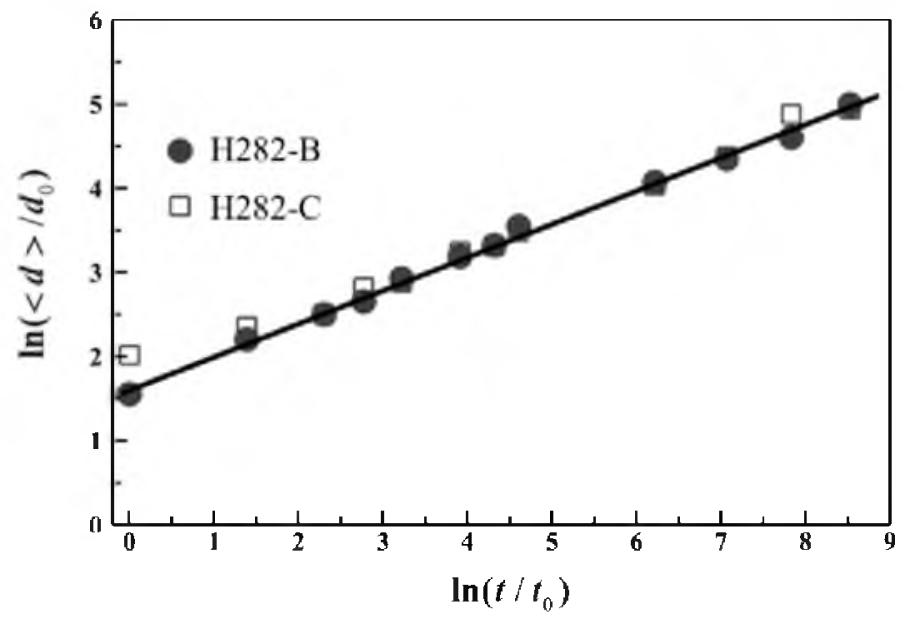

Figure 12: Replot of $\ln \left(<d>/ d_{0}\right)$ versus $\ln \left(t / t_{0}\right)$ for coarsening of $\gamma^{\prime}$ in H282-B and H282-C shows a quasi-linear relationship. The solid line is the linear fit of H282-B (as a visual aid), where $d_{0}=1 \mathrm{~nm}$ and $t_{0}=1$ hour.

It is difficult to make direct comparison of the simulated alloys and their coarsening behavior with the experimental alloys because of the simplifying assumptions made in their development. However, if the Ti/Al ratio is examined, the \# 2 simulant alloy has a ratio of 1.167 . The \#6 simulant alloy has a $\mathrm{Ti} / \mathrm{Al}$ ratio of 1.667 . Conversely, $\mathrm{H} 282-\mathrm{B}$ has a $\mathrm{Ti} / \mathrm{Al}$ ratio equivalent to 1.748 , or a ratio that is more similar to the \#6 simulant alloy. The H282-C alloy has a ratio of 1.260 , or a value similar to that of the \#2 simulant alloy. From the simulation results shown in Figure 4, the \#2 and \#6 alloys have similar $\gamma^{\prime}$ particle sizes through about 100 hours, after which the \#2 simulant coarsens at a more rapid rate. The H282-C alloy indeed does coarsen more rapidly through about 2252 hours of exposure. However, it is hard to make a direct comparison with the phase field results because the phase field simulations stopped at 200 hours. At the 200 hour mark, there is about a $15 \mathrm{~nm}$ difference between \#2 and \#6 simulants which does not show up in the experimental results. Also, there may be a change in the coarsening rate for H282-B and $\mathrm{H} 282-\mathrm{C}$ that is not reflected in the phase field simulations for the duration examined. At this time one more experimental sample will be extracted at 10,000 hours. This additional data may clarify experimental trends in the $\gamma^{\prime}$ coarsening behavior.

\section{Conclusions}

The coarsening behavior of $\mathrm{H} 282$ with two different $\mathrm{Ti} / \mathrm{Al}$ ratios has been examined using phase field modeling techniques and experimental isothermal annealing experiments. General trends have been established and some correspondence between phase field modeling simulations and the coarsening in real alloys have been noted. However, the phase field simulations are only of short duration (200 hours). While they show trends at the beginning of the particle growth process, they do not necessarily reflect longer term behavior. This will need to be examined in more detail. Also, important will be refinement of the phase field model in terms of starting particle size to bring the results more in line with what is observed experimentally. Of a more 
practical nature, preliminary analysis of the experimental data on $\gamma^{\prime}$ particle coarsening has shown the possibility that trans-interface-diffusion-controlled (TIDC) coarsening may be the operable mechanism. In TIDC there exists a different regime at the interface between particle and matrix which serves as a "bottleneck" for diffusion, causing deviation from the classical LSW theory.

\section{Disclaimer}

This report was prepared as an account of work sponsored by an agency of the United States Government. Neither the United States Government nor any agency thereof, nor any of their employees, makes any warranty, express or implied, or assumes any legal liability or responsibility for the accuracy, completeness, or usefulness of any information, apparatus, product, or process disclosed, or represents that its use would not infringe privately owned rights. Reference herein to any specific commercial product, process, or service by trade name, trademark, manufacturer, or otherwise does not necessarily constitute or imply its endorsement, recommendation, or favoring by the United States Government or any agency thereof. The views and opinions of authors expressed herein do not necessarily state or reflect those of the United States Government or any agency thereof.

\section{References}

1. R. Viswanathan, J.F. Henry, J. Tanzosh, G. Stanko, J. Shingledecker, B. Vitalis, and R. Purgert, "U.S. Program on Materials Technology for Ultra-Supercritical Coal Power Plants," J. Mater. Engr. Perform., 14 (2005) 281-292.

2. R. Viswanathan, A.F. Armor and G. Booras, "A Critical Look at Supercritical Power Plants," Power, 4 (2004) 42-49.

3. http://www.netl.doe.gov/technologies/coalpower/advresearch/Ultrasupercritical.html

4. Superalloys II, C.T. Sims, N.S. Stoloff, and W.C. Hagel, Eds. (New York, NY: John Wiley \& Sons, 1987).

5. P.D. Jablonski and C.J. Cowen, "Homogenizing a Nickel-Based Superalloy: Thermodynamic and Kinetic Simulation and Experimental Results," Metall. Trans. B, 40 (2009) 182-186.

6. http://www.sentesoftware.co.uk. Sente Software Ltd., Surrey, United Kingdom.

7. K. Wu, Y. Wen, and J.A. Hawk, "Phase Field Simulations on the Precipitation Kinetics of $\gamma^{\prime}$ in Ni-Base Superalloy Haynes 282," TMS2013 Supplemental Proceedings (Hoboken, NJ: John Wiley \& Sons, Inc., 2013; doi: 10.1002/9781118663547.ch88).

8. J.O. Andersson and J. Ågren, "Models for Numerical Treatment of Multicomponent Diffusion in Simple Phases," J. Appl. Phys., 72 (1992) 1350-1355.

9. C.E. Campbell, W.J. Boettinger and U.R. Kattner, "Development of a Diffusion Mobility Database for Ni-Base Superalloys," Acta Mater., 50 (2002) 775- 
10. S.L. Chen, S. Daniel, F. Zhang, Y.A. Chang, X.Y. Yan, F.Y. Xie, R. Schmid-Fetzer, and W.A. Oates, "The PANDAT Software Package and Its Applications," CALPHAD: Computer Coupling of Phase Diagrams and Thermochemistry, 26 (2002) $175-$.

11. THERMOCALC, Version 3.1 (Stockholm, Sweden: Royal Institute of Technology, 2013).

12. W.S. Rasband, ImageJ: http://imagei.nih.gov/ii//(Bethesda, MD: U. S. National Institutes of Health, 1997-2014).

13. S.A. Saltikov, "The Determination of the Size Distribution of Particles in an Opaque Material from a Measurement of the Size Distribution of Their Sections," Proc. $2^{\text {nd }}$ Int. Cong. Stereology, 1967, 163-173.

14. L. Corte and L. Leibler, "Analysis of Polymer Blend Morphologies from Transmission Electron Micrographs," Polymer, 46 (2005) 6360-6368.

15. I.M. Lifshitz and V.V. Slyozov, "The Kinetics of Precipitation from Supersaturated Solid Solutions," J. Phys. Chem. Solids, 19 (1961) 35-50.

16. A.J. Ardell and V. Ozolins, "Trans-Interface Diffusion-Controlled Coarsening," Nat. Mater., 4 (2005) 309-316.

17. A.J. Ardell, "Trans-Interface-Diffusion-Controlled Coarsening of Gamma ' Precipitates in Ternary Ni-Al-Cr Alloys," Acta Mater., 61 (2013) 7828-7840. 